\title{
Influence of preloading on formation of adiabatic localized shear in copper
}

\author{
V.A. Pushkov, A.V. Yurlov, A.M. Podurets, A.N. Tsibikov, K.P. Novikov, and M.A. Pukhov \\ Russian Federal Nuclear Center - VNIIEF, 607190, Sarov, Nizhniy Novgorod region, Russia
}

\begin{abstract}
This paper is devoted to results of investigation of localized shear in as-received copper, and which was subjected to preliminary quasi-isentropic shock loading by the pressure of $\sim 30 \mathrm{GPa}$. Tests were performed with hat-shaped samples by the Split Hopkinson Pressure Bar method (SHPB). The authors present estimation of quantitative characteristics of localized shear in tested materials (shear stress, relative shear strain, shear band width, relative strain rate in shear band). The paper includes data of metallographic investigations of the tested samples. Also the authors made an attempt of numerical simulation of stress field change during formation.
\end{abstract}

\section{Introduction}

The basic mechanism of localized adiabatic shear is a fast local cycle consisting of plastic strain of materials, transition of work into heat and thermal softening of materials, for example [1]. It is found in the works of the investigators that a creation of centers for localizing deformation is very sensitive to initial defect density and construction of a microstructure. Coincidentally with this the works of H.C. Rogers [2], K.A. Hartley [3], R.J. Clifton [4] and others have revealed that the capacity of a material for strain hardening plays a great role in localization of shear bands. Competition between phenomena of hardening and softening gives control over nucleation and development of shear bands. In addition H.C. Rogers has presumed that the materials having high hardening rates, such as copper and aluminum are less subject to adiabatic shear, including under the conditions of a very high strain rate [2]. In general it is assumed that the materials with high strength and low capacity for strain hardening have a great tendency to the formation of localization of adiabatic shear bands. The effect of preliminary shock deformation makes a significant impact on dynamic mechanical properties of materials [5]. In particular, the researchers revealed a rise in stresses of a plastic flow, for instance [6] for copper and a series of other metals, alloys and composites after preliminary shock deformation at subsequent dynamic loading. The effect of preliminary shock deformation on a growth of localized shear in steel 304 was studied in detail by G.T. Gray III, Q.Xue and others in [7] with use of split Hopkinson bar method (SHPB). It has been obtained as a whole that pre-deformed steel 304 is more prone to shear localization than annealed steel (localized shear was formed at distinctly lesser plastic displacements and stresses) [7].

The present paper is devoted to the results of the study of localized shear in copper, subjected to tentative highspeed quasi-entropic loading by pressure of $30 \mathrm{GPa}$, when compared to the data on copper in as-delivered condition. Tests were performed on hat-shaped samples [8] when applying the method of SHPB $[7,9,10]$.

\section{Material and procedure of studies}

We have previously implemented the study of the formation of localized shear in copper M1 in as-delivered

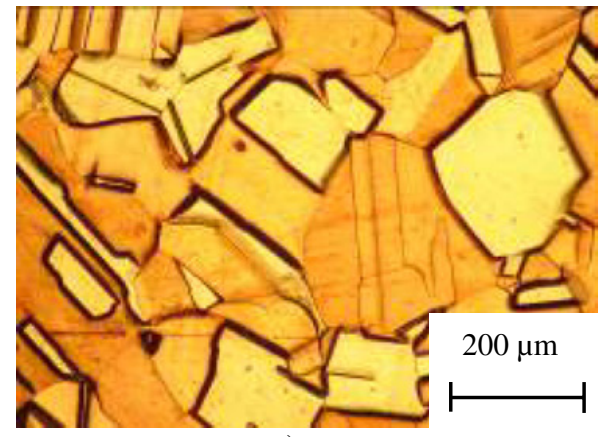

a)

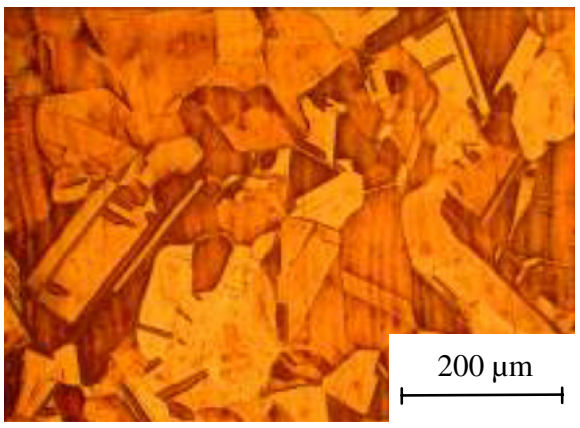

b)

Fig. 1. Initial microstructure of copper M1 in as-delivered condition (a) and after preloading (b).

condition on samples with the overall dimensions of $\emptyset 10 \times$ $5 \mathrm{~mm}$ [10]. The structure of this copper is characterized by a large grain size of $\sim 110 \mu \mathrm{m}$. Identical copper M1 in as-delivered condition was subjected to preloading of quasi-entropic compression wave with pressure amplitude of $30 \mathrm{GPa}$ in special tests. Figure 1 presents photos of the initial copper structure in as-delivered condition and after preloading.

Copper structure after high-speed quasi-entropic loading is characterized by the emergence of a greater quantity of twins, uniformly positioned along the sample (figure 1b). As depicted in [11] such twins are formed in copper by pressure of higher than $20 \mathrm{GPa}$ at dynamic loading and with a strain rate of more than $10^{6} \mathrm{~s}^{-1}$. The formation of a great deal of twins increases strength characteristics of materials [11]. The similar data, but with 


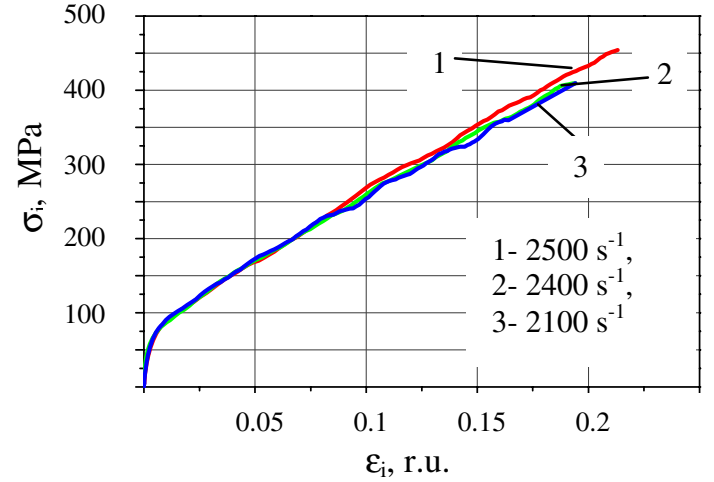

a)

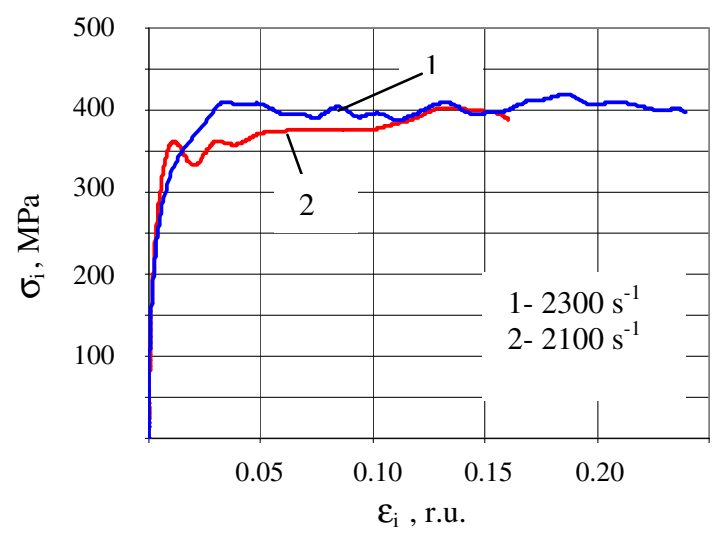

b)

Fig. 2. Dynamic compression diagrams $\sigma_{i}-\varepsilon_{i}$ for copper in asdelivered condition ( a) and after quasi-entropic loading (b); tests by SHPB method.

the appearance of intragranular parallel bands of localized strain, were revealed for copper after shock-wave loading by pressure of $30 \mathrm{GPa}$ [11].

Dynamic compression diagrams for these two types of copper at strain rates of 2100-2500 s $\mathrm{s}^{-1}$ were constructed in true coordinates of $\sigma_{i} \varepsilon_{I}$ and they are presented in figure 2 .

In accordance with the shown curves we notice that copper M1 in as-delivered condition possesses a considerable strain hardening at dynamic compression. Following quasi-entropic loading, copper yield strength increased a five times and a degree of strain hardening showed a decrease greatly (see figure 2). Analogous changes in material reaction subsequent to shock-wave loading were discovered on other metals, for example in steel [7].

The procedure with use of the SHPB method (figure 3a) is described in detail in [10]. Some peculiarities should be stressed for tests with previously loaded copper. All sizes of samples used by us earlier [10] were decreased proportionally by a factor of 1.4 on account of small dimensions of blanks. Hat-shaped samples were applied with a predetermined direction of forced shear. Samples geometry was given in figure $3 \mathrm{~b}$. Hopkinson bars were made of strong martensitic-aging steel. Load pulses $\sigma(\mathrm{t})$ in a loading bar were created by impactors made of KHVG steel (20 mm in diameter, $100-250 \mathrm{~mm}$ in length), accelerated by using a pneumatic gun up to a velocity of $3.8-4.6 \mathrm{~m} / \mathrm{s}$. The durations of the pulses were $40-100 \mu \mathrm{s}$.

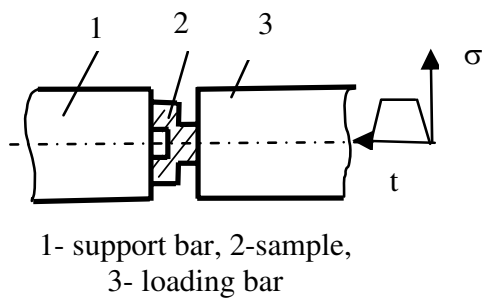

a)

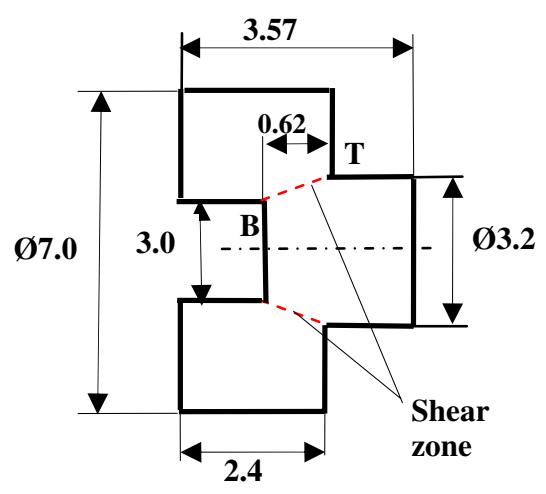

b)

Fig. 3. Diagram for performing tests (a) and samples geometry (b).

Copper M1 (as received)

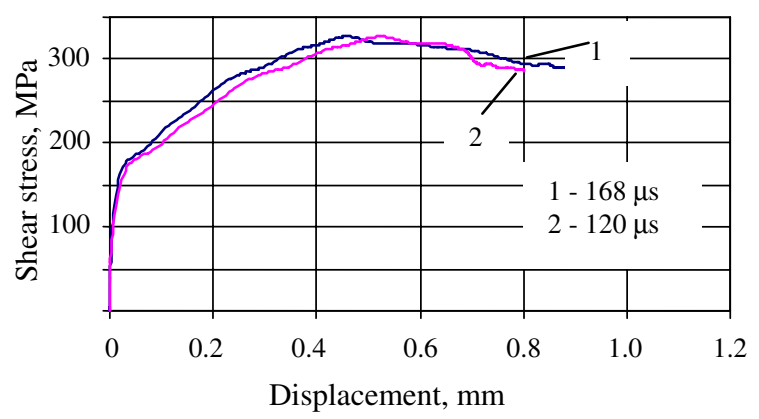

Fig. 4. Shear stress depending on displacement for copper in as-delivered condition.

Displacement of samples ends relative to each other and shear stress in a sample were determined when using strain pulses being recorded by the help of strain gages on bars. A shear component of loading was defined based on sample's geometry without regard for expansion effect of a cylindrical base of the sample [10]. Shear stress was calculated on the basis of the supposition that a shearing force is exerted only at shear section between two edges of a sample (section of T-B in figure 3b).

\section{The results of the investigations}

Figure 4 presents the diagrams of "shear stress-displacement" in tests with copper in as-delivered condition, which we obtained in [10] with the help of impactors 300 and $420 \mathrm{~mm}$ long at the velocities of $4.5 \mathrm{~m} / \mathrm{s}$ and $5.3 \mathrm{~m} / \mathrm{s}$ respectively. The duration of pulses was $\mathrm{t}=168 \mu \mathrm{s}$ and $120 \mu \mathrm{s}[10]$. 


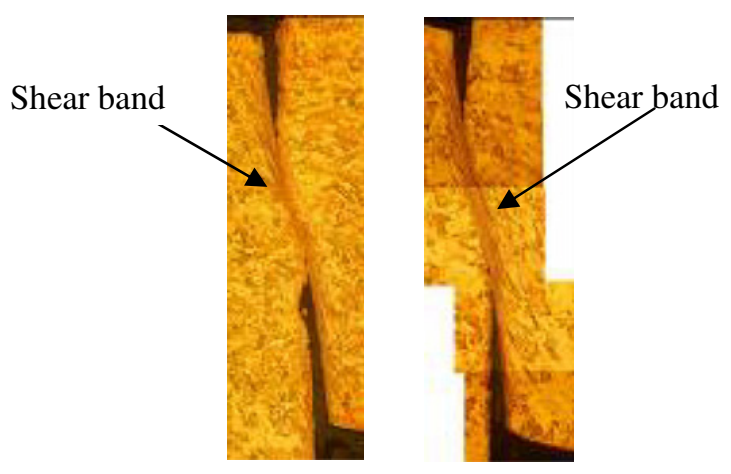

Fig. 5. Microstructure of shear zone in copper M1 in as-delivered condition. Width of localized shear band is $30 \mu \mathrm{m}$ (on the left) and $40 \mu \mathrm{m}$ (on the right) [10].

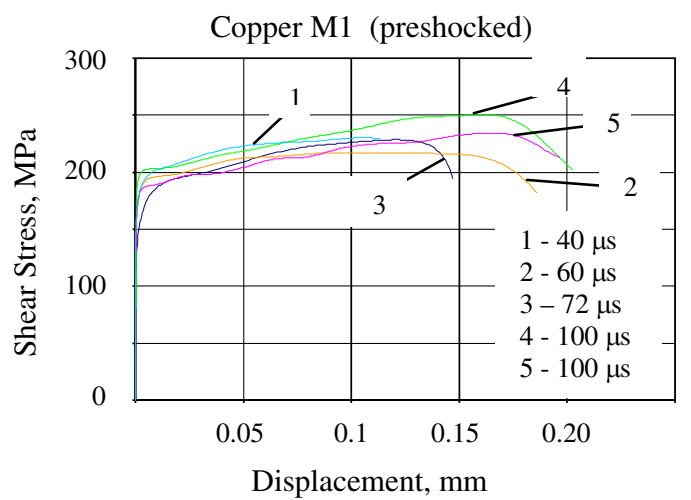

Fig. 6. Shear stress depending on displacement for pre-loaded copper.

As noted in [10], the gained diagrams show a state of capability satiation for strain hardening and point to a quantity of a critical stress. Beginning with this critical stress the processes of softening and processes of forming localized shear start to be dominant at further deformation. This stress amounts to $\sigma_{\text {sh }}=325 \mathrm{MPa}$. Figure 5 presents a microstructure of shear zones in these tests [10]. A shear band ranges in width from $30 \mu \mathrm{m}$ to $40 \mu \mathrm{m}$.

Relative shear strain $\varepsilon_{\text {sh }}$ can be defined from formula

$$
\varepsilon_{\text {sh. }}=X_{\text {rel. }} / h
$$

where $X_{\text {rel. }}$ is the relative displacement inside of a shear band, $h$ is the width of a shear band [7]. $X_{\text {rel }}$ is determined as a difference between maximum displacement $X_{\max }$, found by using the diagram "shear stress-displacement", and critical displacement $X_{\text {crit., at which a shear band }}$ starts to arise. A relative strain rate may be assessed through division of relative shear strain by time of shear localization [7]:

$$
\varepsilon_{\mathrm{sh} .} / t_{\mathrm{sh}}
$$

From formulae (1) and (2) relative shear strain $\varepsilon_{\text {sh. }}$ is 11.7 r.u. and 8.75 r.u. in these tests, and relative strain rate $\varepsilon$ is $0.65 \times 10^{5}$ and $0.54 \times 10^{5} \mathrm{~s}^{-1}$ for the band of width $h$ $30 \mu \mathrm{m}$ and $40 \mu \mathrm{m}$ respectively.

Figure 6 presents dependencies of shear stress upon a displacement in tests with copper M1, subjected to quasientropic preloading.

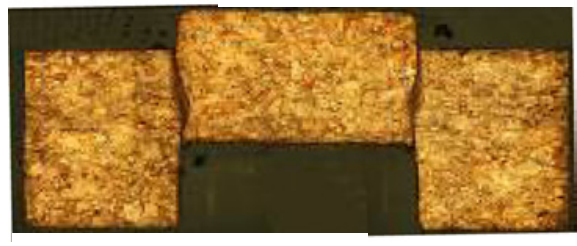

a)

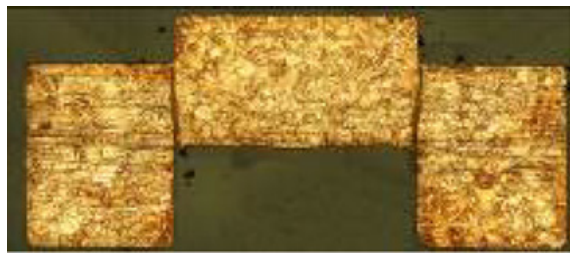

b)

Fig. 7. Microstructure of samples of pre-loaded copper after tests: a) $\left.\mathrm{V}_{\text {imp. }}=3.8 \mathrm{~m} / \mathrm{s}, \mathrm{t}=60 \mu \mathrm{s} ; \mathrm{b}\right) \mathrm{V}_{\text {imp. }}=4.2 \mathrm{~m} / \mathrm{sc}, \mathrm{t}=100 \mu \mathrm{s}$.

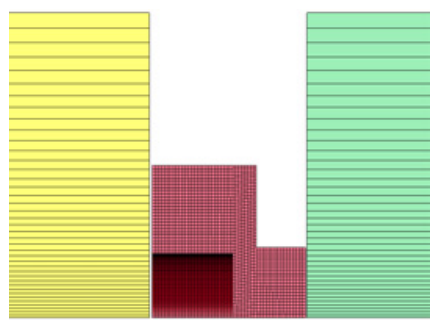

Fig. 8. Design diagram of experiment.

This is evident on the basis of curves 2-5, of figure 6 that in these tests after achieving a maximum (critical) stress material softening takes place and therefore shear localization must be occurred. This was confirmed with the help of a metallographic analysis. Some bands of localized shear were observed in samples at durations of loading $60-100 \mu \mathrm{s}$, in so doing a width of bands $h$ ranged from $80 \mu \mathrm{m}$ to $40 \mu \mathrm{m}$. The bands possess enhanced strength and they are saturated with defects, a grain structure has been disrupted in them. As an illustration, figure 7a shows a photo of a microstructure of a copper sample, proven at the impactor velocity of $3.8 \mathrm{~m} / \mathrm{s}$ and a duration of a pulse of $\mathrm{t}=60 \mu \mathrm{s}$, and in figure $7 \mathrm{~b}-$ at the impactor velocity of $4.2 \mathrm{~m} / \mathrm{s}$ and $\mathrm{t}=100 \mu \mathrm{s}$.

It was obtained that a band of localized shear is wider $(80 \mu \mathrm{m})$ at a short pulse (figure $7 \mathrm{a})$ than at a longer pulse. Here we can see a zone of great shear deformations, grains were subjected to strong plastic deformation in this area. A band width reaches $40 \mu \mathrm{m}$ at a longer pulse (figure $7 \mathrm{~b}$ ), a developed shear band is evident in a shear zone, and grains are strained far less in a zone adjacent to a band. Visible distortions are not observed in a grain structure at a distance of $50 \mu \mathrm{m}$ from a band edge. As a whole, it was obtained at in these tests that critical shear stresses are $\sigma_{\text {sh. }}=225-250 \mathrm{MPa}$, and critical displacements are $X_{\text {crit. }}=0.14-0.17 \mathrm{~mm}$. Spread of quantities $\sigma_{\text {sh. }}$ and $X_{\text {crit. }}$, apparently, is associated with various values of defect density in a small zone of forced shear of samples after preloading. The evaluation showed that relative shear strain $\varepsilon_{\text {sh. }}$ is $0.5,0.58,0.7,0.9$ r.u. here, and relative strain rate 


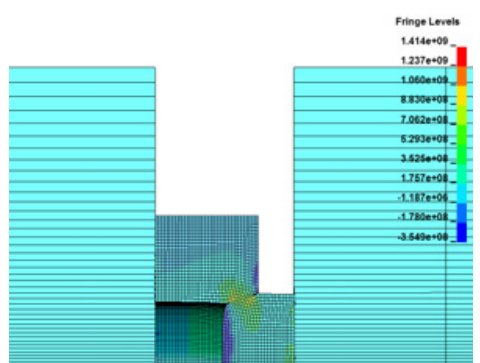

a)

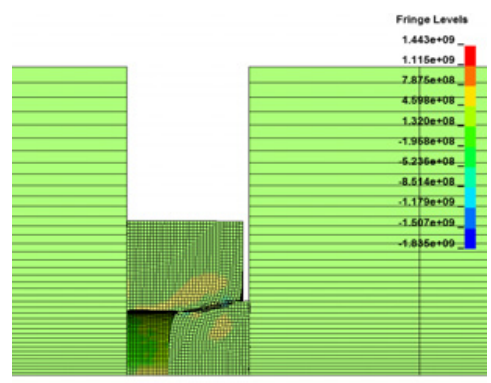

b)

Fig. 9. Stress fields at $\mathrm{t}=120 \mu \mathrm{s}$ (a) and $\mathrm{t}=200 \mu \mathrm{s}$ (b).

is $\varepsilon^{\prime}=(0.36,0.4,0.5,0.7) \times 10^{5} \mathrm{~s}^{-1}$ for the band having $h=80,68,51,40 \mu \mathrm{m}$ accordingly.

A comparison of diagrams in figure 4 and figure 6 shows that plastic shear strain begins in both materials approximately at the same stresses of 170-200 MPa under similar conditions of loading. At the same time shear localization commences for preloaded copper at critical stresses of $225-250 \mathrm{MPa}$, and the stress is $\sim 325 \mathrm{MPa}$ for copper in as-delivered condition. In such a manner, a localized shear band exists at a smaller stress in similar conditions of loading for preloaded copper. The obtained results are in agreement with the data of work [7], where analogous results are observed in tests with steel 304 SS.

\section{Numerical simulation of process}

The experiment was simulated, in which the sample of diameter $10 \mathrm{~mm}$ and of height $5 \mathrm{~mm}$ and made of copper M1 in as-delivered condition was being loaded by the impactor $420 \mathrm{~mm}$ long with a velocity of $5.3 \mathrm{~m} / \mathrm{s}$. The calculations were performed by using a three-dimensional version of the LSD/DINAMIKA-3 program. Figure 8 demonstrates a computational grid of the experimental assembly. Finiteelement discretization for loading bars and the impactor was implemented nonuniformly with grid crowding in a direction of a symmetry axis of the assembly.

Figure 9 demonstrates stress fields obtained in calculations at various instants of time in a process of sample's deformation.

From figure 9 it follows that the use of the threedimensional technique has made it possible to calculate a process of sample's deformation qualitatively. According to the results a satisfactory agreement was achieved between the experiment and the calculation using a value of a loading pulse and a value of finite deformation of a copper sample. Design shear stresses exceed experimental ones a little. Here, obviously, a far better agreement may be gained when using more sophisticated models of elastic-plastic deformation, for instance, Johnson-Cook model [12] or a MTS model [13], which take into account the dependence of plastic properties of a material upon deformation and temperature.

\section{Conclusions}

In the investigations of adiabatic localized shear in copper in as-delivered condition and after high-speed quasiisentropic loading $(P=30 \mathrm{GPa})$ through SHPB method the qualitative data were determined: critical shear stress, relative shear deformation, shear band width, relative strain rate in a shear band. The obtained data confirm the inclination found in the studies of localized shear: the preloaded metals being more high-strength, but having a smaller degree of strain hardening possess a higher tendency to a formation of adiabatic shear bands [7]. A model description of deformation agrees satisfactorily with experimental data.

It is necessary to take into consideration such data as initial density of structural defects, temperature and microhardness in a shear band, changes in grain structure in a shear band for a more qualitative description of localized shear in models.

\section{References}

1. A. Molinari, R.J. Clifton, Trans. ASME, E, J. Appl. Mech. 54, 806-812 (1987)

2. H.C. Rogers, Ann. Rev. Mater. Sci. 9, 283-311 (1979)

3. K.A. Hartley, J. Duffy, R.H. Hawley, J. Mech. Phys. Solids, 35, 283-301 (1987)

4. T.G. Shawki, R.J. Clifton, Mech. Mater., 8, 13-43 (1989)

5. D. Chae, J.P. Bandstra, D.A. Koss, Mater. Sci. Eng. A, A285, 165-171 (2000)

6. G.T. Gray, K.S. Vecchio, Metall. Mater. Trans. A, 26A, 2555-2563 (1995)

7. Q. Xue, G.T. Gray III, B.L. Henrie, S.A. Maloy, S.R. Chen, Metall. Mater. Trans. A, 36A, 1471-1486 (2005)

8. K.H. Hartman, H.D. Kunze, L.W. Meyer in Shock Waves and High-Strain-Rate Phenomena in Metals, M.A. Meyers and L.E. Murr eds., 325-337 (Plenum Press, 1981)

9. Q. Xue, G.T. Gray III, Metall. Mater. Trans. A, 37A, 2435-2446 (2006)

10. V.A. Pushkov, A.V. Yurlov, A.P. Bol'shakov, A.M. Podurets, A.V. Kal'manov, E.V.Koshatova, Proceedings of the $9^{\text {th }}$ DYMAT International Conference, Belgium, Brussels, 1, 395-400, (EDP Science, 2009)

11. A.M. Podurets, V.A. Raevsky, V.G. Khanzhin et al., Physics of Combustion and Explosion (Rus.), 47, 5, 123-131 (2011)

12. G.R. Johnson, W.H. Cook, Proc. $7^{\text {th }}$ Intern. Symp. Ballistics, Netherlands, Am. Def. Prep. Org., (ADPA, 1983)

13. P.S. Follansbee, U.F. Kocks, Acta Metall, 36, 81-93 (1988) 